\title{
Forest Loss, Monetary Compensation, and Delayed Re-planting: \\ The Effects of Unpredictable Land Tenure in China
}

\begin{abstract}
Over the past 65 years, forest tenure in China has oscillated unpredictably between private and village property regimes. This policy-induced uncertainty has distorted the harvesting decisions of individuals granted rights to grow trees and has lowered the value of China's forest output. We provide an analytical framework for assessing these effects quantitatively. Understanding the consequences of this policy-induced uncertainty is particularly important since China is currently engaged in an ambitious plan to increase its domestic supply of timber. To conduct this analysis, we extend the literature on forestry economics when there is a risk of loss due to forest fire or pests. We (1) take account of the possibility that replanting can only resume after an interval of uncertain length (with immediate replanting as a special case); (2) investigate the effects of compensation for such losses based only on the net value of the stand of trees at the time of the loss; and (3) compare it to compensation that would leave the wealth and rotation decisions of the farmer unaffected by the presence of uncertainty.
\end{abstract}

Key Words: forest tenure risk; Faustmann model; optimal rotation period under uncertainty; full compensation for loss

JEL Classification Numbers: Q23, Q28 


\section{Introduction}

Approximately $40 \%$ of China's rural population uses fuelwood as the major energy source. At the same time, the booming Chinese economy requires everincreasing amounts of forest products. In 2010, China consumed the most woodbased panels, recovered paper, paper, and paperboards in the world and was the second-greatest consumer of industrial roundwood, sawnwood, and pulp for paper (FAO 2012).

Yet compared with other countries, China is poorly endowed with forests. China has only 0.145 hectare of forests per capita, barely one-fourth of the world average (FAO 2010). Moreover, forests cover 20.4\% of China's surface area (SFA 2010), less than two-thirds of the world average.

Trees in China are grown in either state-owned or nonstate forests. In stateowned forests, both the land and the trees are the property of the state; these forests are controlled by state logging enterprises, state forest farms, and natural reserve agencies, and harvesting decisions are made by state-owned forest agencies. In nonstate forests, which represent $60 \%$ of the forest area nationally, the land is officially owned by village collectives (Xu et al. 2004), but the trees can be managed by the collectives, individual private households, or different private-public arrangements (Demurger et al. 2009, pp. 20).

Virtually all of China's fuelwood is grown domestically. In addition, China imports timber from neighboring subtropical countries to satisfy other demands of its growing economy. Its aggressive policy of importing timber has led to unsustainable exploitation of the resources of neighboring countries (Xu and White 
2004). In an endeavor to increase the domestic supply of forest products, China has launched the most ambitious reforestation efforts in the developing world (Bennett 2008).

These reforestation efforts have been directed toward China's nonstate forests. Historically, the state forests were China's major source of timber, as they contained most of the good quality, old-growth forests. Since the early 1980s, however, most state-owned natural forests have suffered from serious deforestation and have been retired from harvesting. As timber output from state forests has declined, the development of nonstate forest plantations has become increasingly important (Xu et al. 2004). Over the past two decades, China has dedicated great effort to developing plantations, and it now has the largest area of forest plantation in the world (SFA 2010). It was originally expected that these nonstate reforestation projects would increase China's forested area by $10 \%$ to $20 \%$ (Bennett 2008). However, it is shown that farmers in the field have little confidence in the government's reforestation plan (Wen et al. 2010 p. 101; Yin and Xu 2002 p. 1765). ${ }^{1}$

Their lack of confidence is understandable, given recent history. A farmer in the southern nonstate forest region who turned 20 in 1950 may have experienced four major upheavals during his lifetime. At 20, he would have received a piece of forestland thanks to the government's policy of distributing plots of equal size to every adult farmer. Six years later, in 1956, he would have lost the use of this land because the people's commune expropriated it, although he might have been

\footnotetext{
${ }^{1}$ For readers who might wonder whether farmers' confidence has returned since the cited papers were published, we conducted our own survey on this issue and found that the utter lack of confidence in the future security of the use rights which these authors had noted remains (Yu, 2013, p. 179)
} 
compensated for the net value of the trees he was forced to relinquish. Upon celebrating his $51^{\text {st }}$ birthday in 1981 , he might have regained the use right of the same forestland, or a piece of land with comparable value and area, when it was returned to him as a family plot. Some trees may have been left on the plot, although they would have been badly managed. However, the land might have been taken back a second time in 1987 by the village collective when he was 57 . He probably would not have received any compensation, as he may have 31 years earlier, because the land on which he had planted trees had been previously reclassified in 1956 as collective (government) property, and thus the expropriated trees on the land would not have required compensation. If he reached the age of 78 , he might have enjoyed the 2008 round of privatization, which again returned plots of equal size to individual farmers. Perhaps the farmer's one allotted child will be able to harvest the trees his father planted before the next expropriation occurs.

We summarize the major transitions in Table 1 and describe each more fully in the Appendix I. Readers wishing a more detailed account of the tenure and management of nonstate forests in China since 1950 are referred to the full-length article on the subject by Liu (2001), who concludes this comprehensive history with the following observation:

Policies for forest tenure and management have changed frequently in China since 1950, causing a complete lack of confidence on the part of villagers in tenure security....(Liu 2001, pp. 257)

Tenure uncertainty in China has become a major barrier to its current policy to promote domestic forest conservation and provide a sustainable supply of forest 
products. ${ }^{2}$ The harm from such frequent and unpredictable policy changes,

however, is hidden from view: it is the foregone net value of the trees that could

have been harvested over time had the policy environment been stable. It is

especially important that these opportunity costs be assessed given China's current

attempts to become less dependent on imports of wood products through its

reforestation efforts.

Table 1. Radical Transitions in Property Rights Regimes of China's Nonstate Forests

\begin{tabular}{|c|c|c|}
\hline Time period & $\begin{array}{l}\text { Property } \\
\text { regime }\end{array}$ & Key features and events \\
\hline $1950-1955$ & Private $^{3}$ & $\begin{array}{l}\text { 1. Under the Land Reform Campaign, the government confiscated } \\
\text { most privately owned forestlands and equally distributed them to } \\
\text { individual rural households. } \\
\text { 2. Elementary cooperatives were established in 1953, and farmers } \\
\text { were encouraged to pool their means of production, including } \\
\text { forestland, although they remained as the owners of land. } \\
\text { 3. Private ownership and household management of forests were } \\
\text { dominant throughout this period }\end{array}$ \\
\hline $1956-1980$ & Village & $\begin{array}{l}\text { 4. The government terminated private ownership of forests after } \\
\text { establishing advanced cooperatives. } \\
\text { 5. Rural households were compensated with the value of forests. } \\
\text { 6. Collective ownership and management of the forests were } \\
\text { dominant. } \\
\text { 7. The Great Leap Forward led to excessive deforestation in forest } \\
\text { collectives. Villages cut trees as fuel for village-based steel } \\
\text { furnaces in an irrational attempt to match British industrial } \\
\text { output. } \\
\text { 8. Non-timber trees and trees planted around homesteads were } \\
\text { once returned to individual households but were re-collectivized } \\
\text { during the Cultural Revolution. }\end{array}$ \\
\hline
\end{tabular}

\footnotetext{
2 For further discussion of tenure uncertainty in the nonstate forests with the land use right oscillating between the village and the household, see Demurger et al. (2009).

3 Private property of land was abolished in China in 1956. We use the term "private property" as a shorthand to mean that the farmer was granted the legal right to use the land for a certain period for the purpose of growing trees and was granted full ownership of products on the land, the priority to renew the land-leasing contract, and even the right to re-rent his use right to others. However, unlike a full owner of private property, he was prevented from free purchase and sale of land. When the use right of the farmer is transferred to the village, we refer to the state as "village property." Ownership of forests by villages in China has not resulted in the free-forall envisaged by Hardin (1968) nor the self-regulated democratic organizations studied by Ostrom (1990). Village collectives are in fact the lowest level administration agencies. In these collectives, decision making is usually based on top-down administrative orders, rather than collective consensus. Massive deforestation has resulted from the transfer of land use rights to village collectives.
} 


\begin{tabular}{|c|c|c|}
\hline 1981-1986 & Private & $\begin{array}{l}\text { 9. The "Three Fix" policy stipulated that the right of collective forest } \\
\text { management should be contracted to individual households, } \\
\text { although forestland was still nominally collective property. } \\
\text { 10. Forest resources with undisputed ownership claims were to be } \\
\text { returned to their original owners. } \\
\text { 11. Degraded and waste forestland was to be equally allocated to } \\
\text { individual households. }\end{array}$ \\
\hline $1987-2007$ & Village & $\begin{array}{l}\text { 12. The government suspended privatization and restored a } \\
\text { collective regime in some regions. } \\
\text { 13. No compensation was paid in this round of collectivization. } \\
\text { 14. No clear-cutting was reported associated with this round of } \\
\text { collectivization. }\end{array}$ \\
\hline 2008-? & Private & $\begin{array}{l}\text { 15. The government initiated a new round of privatization in } 2003 \\
\text { and has expanded it to a national scale in } 2008 \text {. } \\
\text { 16. This round of privatization aims at devolution of forest } \\
\text { management to individual rural households. }\end{array}$ \\
\hline
\end{tabular}

To assess these opportunity costs requires a model. Yet the forestry models in the literature cannot contribute to this policy analysis without significant modification. All forestry models are descendants of the seminal article by Faustmann (1849), who examined the wealth-maximizing sequence of harvesting decisions of someone who owns a plot of land over an infinite horizon and plants an even-aged stand of trees every time he cuts one down. Faustmann's model applies to the Chinese situation where an infinitely-lived family maximizes the sum of the discounted profits earned from the trees on land to which it has use rights. Taking the stationary price as given, it is optimal to harvest the stand of trees when the value of letting it grow another year equals the interest lost by postponing for a year not only the sale of the wood but also the net revenue from future harvests.

Although Faustmann's original model assumes certainty, more recent contributions have abandoned that assumption and have examined the effects on rotation decisions of introducing uncertainty. The forms of uncertainty most closely related to our contribution arise from natural hazards and from expropriation. 
Natural hazards such as fires, ice and windstorms, and pest attacks can destroy forest stock. Reed (1984) asked how the risk of a forest fire would affect harvesting decisions. He used a Poisson stochastic process to describe the catastrophic events and assumed they occur independently and randomly. Reed implicitly assumed that the harvester was completely uninsured and that he could immediately re-plant following the disaster. He concluded that the presence of fire risk increases the effective discount rate and shortens the optimal rotation periods. The Poisson process has been used to explain many other natural threats, such as hurricane (Haight et al. 1995) and soil degradation (Routledge 1987). These researchers all reach the same conclusion: it is optimal to cut trees at an earlier age if the risk of a natural disaster increases. More recently, Yoder (2004) has shown that with sufficient protection efforts and a salvage value that is high enough, rotation age may be extended.

The risk of expropriation can also affect harvesting decisions. Yin and Newman (1997) examined empirically the impact on the forest section of China's rural reform. They found that in regions with severe tenure insecurity, forest growth was limited. Amacher et al. (2009) show that expropriation risk creates incentives for agricultural clear-cutting and short-term harvesting. Qin et al. (2011) conducted a survey-based choice experiment with 210 Chinese farmers. The results show that reduced perceived risk of contract termination can significantly increase farmers' willingness to pay for a forest contract. ${ }^{4}$

\footnotetext{
${ }^{4}$ In most cases, the Chinese government granted individual farmers use rights over an equal share of the land free of charge. As the land use right came to be regarded as property, however, farmers granted use rights could rent or sell them to other farmers who wanted to expand their forestry operations. The value of a use right can be regarded as the expected discounted value a farmer would get from renting out his parcel to others wanting
} 
While the introduction of uncertainty into Faustmann's tree-cutting model is a step in the right direction, this literature assumes that the farmer (1) receives no compensation from an insurance company when his crop is destroyed and (2) can immediately re-plant. Neither assumption is appropriate for many natural disasters, since farmers often receive insurance payments for their losses and some disasters (e.g., oil spills, chemical spills, or nuclear accidents) require a time interval of considerable length before re-planting can occur. We generalize the standard model by introducing as exogenous parameters the expected rate of compensation following a loss and the hazard rate governing the time when re-planting can occur. The contribution of our paper is to characterize the harvesting decisions of individuals granted land use rights that oscillate stochastically between private and village property over infinite time and to use this characterization to clarify the consequences of the government's policy. ${ }^{5}$ Three conclusions are particularly striking.

First, if farmers face a higher risk of transition from private to village property, they may extend rotation periods rather than shorten them as the literature suggests. The literature's conclusion rests on the assumption that farmers are not

to grow trees whenever the right to use that parcel was granted to him plus the expected present value of compensation receipts whenever that right was taken away again.

${ }^{5}$ Long (1975) pioneered in studying the effects of nationalization uncertainty on extraction behavior. In his model, transitions occur only in one direction---from private property to state ownership. To the best of our knowledge, ours is the first paper to consider the behavior of a wealth-maximizer operating under a property rights regime that oscillates stochastically between two states of nature; in our application, the wealthmaximizer is an individual choosing the optimal time to harvest trees (if disposition of them happens to be under his control). We are by no means the first to study optimal behavior in response to other oscillations between two states of nature. Virtually all of the other papers, however, focus on the same question: what storage behavior is optimal when a vital import (e.g., oil, natural gas) oscillates stochastically between being available and unavailable. Bergstrom et al. (1985) and Bahel (2011) assume that the imported good's price is exogenous while Creti and Villeneuve (2013) have endogenized it. The remaining paper, Gaudet and Lasserre (2011), considers optimal usage of two exhaustible resources, a secure domestic resource that can be extracted at low cost and a foreign nonrenewable resource that oscillates stochastically between two costs of extraction, either of which is higher than that of the secure source. 
compensated if lightning or pests destroy their trees; if the loss is insured sufficiently based on the net value of their current stand, however, the result would change. In China, compensation is based on the size of the tree at the time the use right of the stand is taken from the farmer. Whether the increased risk of such expropriation lengthens or shortens the rotation period turns out to depend on the magnitude of such compensation.

Our second conclusion is that compensation based on the net value of the stand at the time of a loss, whether from a forest fire or from expropriation, does not constitute full compensation. We show what would constitute full compensation and that a farmer would be shortchanged if he received compensation based only on the net value of his current stand at the time of his loss.

Third, when properly calibrated, our model can be used to assess the potential gains that China could secure if farmers could grow their trees without the risk of losing the use rights that were granted to them. To illustrate how this could be done, we compare the discounted value of timber harvested (net of harvesting and planting costs) when property rights are guaranteed with the corresponding discounted value when policy oscillates unpredictably. One effect which makes quantification particularly difficult is that farmers may find a different species to be optimal when the environment becomes more secure. For example, trees that grow fast like bamboo would no longer be appropriate when expropriation ceased to be a consideration, and the farmer might switch to species that, despite their slow start at the outset, ultimately attained a more massive volume. In our illustrative simulations, the net wealth is more than twice what nonstate forests currently 
generate. We also present a useful decomposition to identify the sources of this wealth gain.

The next section introduces the model. Section 3 investigates the comparative static effects of changing the compensation rate and the hazard rates governing the transition to and from the village property regime. We also show that compensation which fully insures farmers against expropriation risk would compensate them for more than the net value of their current stand of trees at the time of expropriation. In Section 4, we estimate the gains that would result from the elimination of policy uncertainty. Section 5 concludes.

\section{The Model}

To isolate the effects of stochastic oscillations between property-rights regimes, we make a number of assumptions. We assume that timber is the only forest product and that its price net of logging cost per unit volume is a constant, normalized to one. We assume that the biological growth of timber is deterministic and denote the volume of wood in an even-aged stand of trees of age $t$ (and hence the net value of the stand if it were harvested then) as $f(t)$. We assume $f(t)$ satisfies the following properties: $f(0)=0, f^{\prime}(t)>0, f^{\prime \prime}(t)<0, \lim _{t \rightarrow 0} f^{\prime}(t)=+\infty$, and $\lim _{t \rightarrow+\infty} f^{\prime}(t)=0$. That is, as the stand matures, the volume of marketable wood it contains (and hence its net value) increases but at a decreasing rate. ${ }^{6}$ This implies that the growth rate of the stand $\left(f^{\prime}(t) / f(t)\right)$ declines monotonically as it ages. We assume that the exogenous cost of planting a stand of seedlings (denoted $c$ ) is small enough that farmers expect to make a profit growing trees.

\footnotetext{
${ }^{6}$ As most commercial harvesting occurs before the stand of trees reaches maturity, we do not consider later phases where growth eventually ceases altogether.
} 
Land use rights of an individual, which we refer to somewhat imprecisely as private property, may be given to the village at a random time. Land use rights of the village may later be returned to the farmer at a random time. ${ }^{7}$ We describe these stochastic transitions by an alternating renewal process. We assume that land use rights may be taken away from the farmer with an average transition rate of $\sigma$ per unit time. A larger $\sigma$ therefore corresponds to a shorter expected time until the transition to village property.

Reed (1984) considered an analogous process in which the random arrival of a forest fire sometimes prevents the farmer from reaping what he has sowed. But in Reed (1984), the farmer can immediately re-plant. We consider a more general case where land use rights under a village property regime may stochastically transit back to private property with an average transition rate of $\lambda$. Hence the expected time before replanting can occur after a forest fire (or after a tree-killing infestation or infection) is $1 / \lambda .{ }^{8}$ The Poisson parameters $\sigma$ and $\lambda$ are exogenous and the decision-maker is assumed to know them. These parameters reflect the magnitude of tenure uncertainty.

Agents are assumed to be risk neutral. A private owner of a land use right chooses his rotation period to maximize the expected value of his forest over an infinite horizon. We assume that in computing his expected payoff, the owner takes into consideration that if his land use right is expropriated at a random time in the future, he will expect compensation based on the net current value of the

\footnotetext{
7 It was impossible for farmers to predict the timing of switches between private and village property regimes in China's forest sector, since such switches were compelled by administrative orders. According to Wen et al. ( 2010) "After the Great Leap Forward, policy changes between private and village property rights became more frequent, and no pattern was established..." [p. 101, our translation]

8 To re-produce Reed's case, let $\lambda \rightarrow+\infty$.
} 
expropriated stand. ${ }^{9}$ We also assume that a farmer anticipates that he will subsequently get his right to use the original parcel (or a parcel of equivalent value) back, devoid of trees, after it has remained village property for an unpredictable length of time. This assumption also accords with recent practice. ${ }^{10}$ Finally, we assume that the farmer granted the land use right anticipates that this stochastic cycle will repeat itself endlessly over time.

The expected value of the forest can be expressed as a sum of all discounted future cash flows, from either timber sales or compensations, net of harvesting and planting costs. Future values are discounted continuously at rate $r$. We denote as $V(y)$ the expected value to the farmer if he relinquishes to the village his right to use the parcel when trees on it have age $y$. We denote the expected value of the right to use a plot with no trees on it as $J_{0}$ if the farmer holds the use right. Assuming that $c$ is not so large that growing trees is unprofitable,

$$
J_{0}=\max _{t \geq 0}\left\{\left[f(t)-c e^{r t}+J_{0}\right] e^{-r t} e^{-\sigma t}+\int_{x=0}^{t}\left[V(x)-c e^{r x}\right] e^{-r x} \sigma e^{-\sigma x} d x\right\}>0
$$

That is, the individual will choose harvest time $t$ to maximize his expected wealth, which can be decomposed into the weighted average of two parts. There is a chance of $e^{-\sigma t}$ that if cutting is planned for age $t$, the use right will not yet have been taken away from the farmer. If so, he receives at $t$ the net revenue from tree harvesting of $f(t)$ less the capitalized planting cost $c e^{r t}$. In addition, he also retains the use right

\footnotetext{
${ }_{9}^{9}$ Describing the first round of collectivization, Liu (2001, p. 243) writes: "the advanced cooperatives were required to value private forests in monetary terms and later compensate member households for the forests and trees they contributed. This policy, however, was not strictly enforced for the majority of cases." Accordingly we assume that compensation based on the net value of the stand at the time the farmer lost his use right was paid with probability $\theta$. Hence, the expected compensation when a stand of trees of age $x$ was expropriated is $\theta f(x)$.

10 After the 1956-1980 village management of nonstate forests, China initiated a new round of forestland privatization. One of the components of the reform was to confirm the existing forest boundary and return the trees to the previous owners, if there was no dispute over the property rights (Liu 2001, pp. 247).
} 
to the barren land, which has expected value $J_{0}$. Alternatively, at some time $x \in[0, t)$

before his intended cutting time, a transition to the village property regime occurs.

In that case, he receives the expected value to him of village property with trees on

it of age $x: V(x)$, less the cost of planting the trees he planted but could not harvest, capitalized to the date of transition: $c e^{r x}$. At any time $x$, the likelihood of such a

transition is $\sigma e^{-\sigma x}$. The value of private use right to a piece of barren forest, $J_{0}$, is

defined as the maximized expected value of the discounted sum, as indicated in equation (1).

When the transition to village property occurs, forest owners receive no revenue for the trees they planted. In its place, they receive expected compensation $\theta f(y)$ for $\theta \in[0,1]$. We assume that the trees are clear-cut immediately by the village $^{11}$, and no re-planting occurs. Farmers are then assumed to wait for the stochastic transition to return their former use right to the land, albeit stripped of trees. ${ }^{12}$ Although data in China do not exist to establish the point conclusively, we believe that historically when the use right was returned to the farmer, the land was

\footnotetext{
11 Although strict forest harvest quotas have been announced to prevent excessive logging, they conflicted with farmers' self-interest and were too costly to implement in the field (Cheng, p. 69, 2004). According to the national forestry yearbook of 1998 , timber harvest with quota only accounts for $44 \%$ of the total, and $56 \%$ of timber was harvested without quotas.

12 Ownership of forests by villages in China has not resulted in the free-for-all envisaged by Hardin (1968) nor the self-regulated democratic organizations studied by Ostrom (1990). Village collectives are in fact the lowest level administration agencies. In these collectives, decision making is usually based on top-down administrative orders, rather than collective consensus. Massive deforestation has resulted from such orders. For example, in an attempt to "catch up" with the British, thousands of forests were clear-cut since 1958 to feed the steel furnaces (Liu, 2001 p.244). The disastrous deforestation is reflected in the following statistics: Hubei province lost nearly a third of its forest stock; forest coverage in Sichuan province decreased by more than half; and over one quarter timber volume was destroyed in Anhui province (Liu 2001 p.244; Wen et al. 2010 p. 105-106). The second round of collectivization occurred in 1987, when the privatization during the previous six years was suspended and a collective regime was restored in some regions. Although some innovative collective arrangements were developed in this round, the bureaucratic influence still undermined sound community forest management (Cheng 2004 p.39; Song et al. 2004 p.236). The staffs serving the board of shareholders and the village collective were usually the same group of people. They were active decision-makers and non-official villagers had no choice but to obey their dictates (Cheng 2004 p. 39). Scholars generally agree that collective management of forests in China has been quite ineffective. As long as the village collectives are run by government bureaucrats, rather than community members themselves, they are not really "community based" and deforestation seems likely.
} 
often devoid of trees. As a simplification in the text, we assume that when the farmer loses the use right, the village immediately strips the land of its trees. When the farmer regains the use right, the land is therefore always devoid of trees.

Some readers may find this assumption of village harvesting behavior too strong since, especially recently, farmers have regained use rights to plots with trees still growing on them. In Appendix III, therefore, we generalize our model. We assume that each village harvests trees as soon as they reach exogenous age ${ }_{c}$. Under this more general assumption, the farmer may regain the use right to the land with trees on it (always age ${ }_{c}$ or younger). We then use this Appendix model to assess the sensitivity of our illustrative estimates, reported in Section 4, concerning the potential increase in forest output that could be achieved by eliminating property rights uncertainty.

Under our assumption that the village immediately strips the land of trees, the farmer expects to receive for trees of age $y$ compensation $\theta f(y)$ and then after an interval of mean length $1 / \lambda, J_{0}$. Thus, a tree of age $y$ in a village property regime is worth to the farmer the expected value of the compensation plus the expected present value of its return to private property in the future:

$$
V(y)=\theta f(y)+\int_{x=0}^{+\infty} \lambda e^{-\lambda x} J_{0} e^{-r x} d x
$$

or, equivalently,

$$
V(y)=\theta f(y)+\frac{\lambda}{\lambda+r} J_{0}
$$

Substituting this into equation (1), we obtain the following:

$$
J_{0}=\max _{t \geq 0}\left\{\left[f(t)+J_{0}\right] e^{-(r+\sigma) t}+\sigma \int_{x=0}^{t}\left[\theta f(x)+\frac{\lambda}{\lambda+r} J_{0}\right] e^{-(r+\sigma) x} d x-c\right\}
$$


The right-hand side of equation (3) can be regarded as a mapping $M\left(J_{0}\right)$ from any trial value of $J_{0}>0$ into a possible different real number on the left-hand side of (3). By definition, $M(0)=\max _{t \geq 0}\left\{f(t) e^{-(r+\sigma) t}+\sigma \int_{x=0}^{t} \theta f(x) e^{-(r+\sigma) x} d x-c\right\}$. Since we assume $c$ is sufficiently small, $M(0)>0$. Given any trial value of $J_{0}$, we can find a $\tilde{t}$ that maximizes the objective function. Using the envelope theorem, we conclude:

$$
\frac{d M\left(J_{0}\right)}{d J_{0}}=\left[e^{-(r+\sigma) \tilde{t}}\right] * 1+\left[1-e^{-(r+\sigma) \tilde{t}}\right] \frac{\lambda}{(\lambda+r)} \frac{\sigma}{(\sigma+r)}
$$

Given the Inada condition on $f(t), \tilde{t}>0$. When $\tilde{t}>0,0<\frac{d M\left(J_{0}\right)}{d J_{0}}<1$, since the right-hand side of (4) is then a strictly convex combination of one and a positive fraction less than one. Since the mapping $M\left(J_{0}\right)$ increases from $M(0)>0$ at a rate less than one $\left(M^{\prime}\left(J_{0}\right)\right)$, it crosses the 45 degree line at a unique, strictly positive fixed point. When we mention $J_{0}$ henceforth, we are referring to this unique fixed point (defined below by equation (5) and (6)).

The maximand in equation (3) is then a function of the cutting time $t$. Denote it as $H(t)$. Thus, $H^{\prime}(t)=e^{-(r+\sigma) t}\left[f^{\prime}(t)-(r+\sigma-\theta \sigma) f(t)-r\left(1+\frac{\sigma}{\lambda+r}\right) J_{0}\right]$.

The global optimum of $H(t)$ cannot occur at $t=0$ given the Inada condition on $f(t)$. We now show that $H(t)$ is single-peaked and achieves a global optimum at the unique solution to $H^{\prime}(t)=0$. Since $f(0)=0, \lim _{t \rightarrow 0} f^{\prime}(t)=+\infty$, and $r\left(1+\frac{\sigma}{\lambda+r}\right)$ is constant, $H^{\prime}(0)$ is positive. The last two terms in the square brackets are negative. The first is strictly decreasing and approaches zero as $t \rightarrow \infty$. Hence, there will be some $t$ such that $H^{\prime}(t)$ is zero. Moreover, since the term in square brackets is strictly decreasing, $H^{\prime}(t)$ becomes negative for larger $t$. That means the function of 
$H(t)$ is single-peaked and achieves its global optimum at the unique solution to the following equation:

$$
f^{\prime}(t)=(r+\sigma-\theta \sigma) f(t)+r\left(1+\frac{\sigma}{\lambda+r}\right) J_{0}
$$

Denote this unique solution as $t^{*}$. The left-hand side of equation (5) is the marginal benefit of further delaying harvesting and the right-hand side is the marginal cost of doing so. Since $J_{0}>0, \frac{f^{\prime}\left(t^{*}\right)}{f\left(t^{*}\right)}>r+\sigma-\theta \sigma \geq r$. Hence, it is optimal for the farmer to cut his stand when it is still growing faster than the rate of interest. It follows that if expropriation or a natural catastrophe intervenes before he can harvest the stand, he loses an asset that would have continued to grow faster than the rate of interest until he harvested it.

Substituting $t^{*}$ into equation (3), we obtain:

$$
J_{0}=\left[f\left(t^{*}\right)+J_{0}\right] e^{-(r+\sigma) t^{*}}+\sigma \int_{x=0}^{t^{*}}\left[\theta f(x)+\frac{\lambda}{\lambda+r} J_{0}\right] e^{-(r+\sigma) x} d x-c
$$

Solving for $J_{0}$, we obtain:

$$
J_{0}=\frac{f\left(t^{*}\right) e^{-(r+\sigma) t^{*}}-c+\sigma \theta \int_{x=0}^{t^{*}} f(x) e^{-(r+\sigma) x} d x}{\left[1-e^{-(r+\sigma) t^{*}}\right]\left[1-\frac{\lambda}{(\lambda+r)(\sigma+r)}\right]}
$$

Since $\sigma, \lambda, \theta, r, c$ and $f($.$) are exogenous, the two endogenous variables t^{*}$ and $J_{0}$ are simultaneously determined by equations (5) and (6).

Stochastic properties of an alternating renewal process such as this have been characterized elsewhere. ${ }^{13}$ As for our model's comparative statics, we highlight the most interesting results in Section 3.1, and relegate the others to Appendix II.

13 The stochastic dynamic properties of alternating renewal processes such as ours have been completely characterized by $\operatorname{Cox}(1967, \mathrm{p} .83$, equation 4$)$. The probability $\pi(t)$ that a land use right starting in the private property state returns to that state at time $t$ as $\pi(t)=\frac{\lambda}{\lambda+\sigma}+\frac{\sigma}{\lambda+\sigma} e^{-(r+\sigma) t}$. This probability declines from unity monotonically and approaches the limit $\pi^{*}=\frac{\lambda}{\lambda+\sigma}$. Intuitively, if use rights are rarely returned by the government ( $\lambda$ near zero), $\pi^{*}$ is near zero; if, on the other hand, use rights are almost immediately returned by the government ( $\lambda$ huge), $\pi^{*}$ is near unity. 
Finally we note that our model encompasses as special cases the models of (1) Reed and (2) Faustmann. When $\theta=0$ and $\lambda \rightarrow+\infty$ (the length of the village property phase is zero, and every time landowners plant trees they risk losing their forest property without compensation), equation (5) reduces to $f^{\prime}\left(t^{*}\right)-(r+\sigma) f\left(t^{*}\right)-$ $r J_{0}=0$, and equation (6) reduces to $J_{0}=\frac{(r+\sigma)\left[f\left(t^{*}\right) e^{-(r+\sigma) t^{*}}-c\right]}{r\left[1-e^{-(r+\sigma) t^{*}}\right]}$. These are Reed's conditions. If, in addition, $\sigma=0$, the equation (5) reduces to $f^{\prime}\left(t^{*}\right)-r f\left(t^{*}\right)-r J_{0}=$ 0 and equation (6) reduces to $J_{0}=\frac{f\left(t^{*}\right) e^{-r t^{*}}-c}{\left[1-e^{-r t^{*}}\right]}$. These are Faustmann's conditions (Amacher et al., 2009, p. 20).

\section{What Constitutes Full Compensation}

In this section we compare the expected compensation $(\theta f(x))$ which has traditionally been paid to Chinese farmers when their use right has been expropriated temporarily to the hypothetical compensation which would have induced these farmers to behave as if no expropriation risk existed. Only the latter merits the adjective "full" compensation. As we show, compensation based entirely upon the net value of the current stand at the time of expropriation shortchanges farmers.

We proceed as follows. We first show that farmers anticipating compensation based on the net value of their current stand at the time it is expropriated will adjust their rotation decision in response to the uncertainty that they face; moreover, the value of the use right to cleared land will also depend upon the uncertainty parameters ( $\sigma$ and $\lambda$ ). Sensitivity to these parameters is a tipoff that farmers are not paid "full" compensation. Whether they are overcompensated or undercompensated 
will become clear. Second, we characterize what full compensation would entail. We verify that a farmer anticipating this form of compensation would choose the same rotation age as Faustmann's farmer and would earn the same expected discounted net profits as Faustmann's farmer regardless of the uncertainty parameters ( $\sigma$ and $\lambda$ ). Third, we show that such a farmer would be shortchanged if instead of the full compensation he was anticipating, he received only the net value of the stand $(\theta f(x)$ for $\theta \leq 1)$ at the time of the expropriation.

\subsection{The Effects of the Level of Compensation and Changes in that Level}

In describing the first round of collectivization, Liu (2001, p. 243) writes: "the advanced cooperatives were required to value private forests in monetary terms and later compensate member households for the forests and trees they contributed. This policy, however, was not strictly enforced for the majority of cases."

Liu's observation suggests that farmers in some regions of China may have anticipated compensation with a higher probability than farmers in other regions. Our model predicts that, ceteris paribus, the expected wealth of the farmers more likely to be compensated would be higher $\left(d J_{0} / d \theta>0\right)$ and that, since they would be better compensated if extending the rotation period resulted in loss of their use right, they would delay longer before harvesting their trees $\left(d t^{*} / d \theta>0\right)$.

To determine formally the effect of increasing the compensation rate $\theta$ on the optimal rotation age, we differentiate (5) with respect to $\theta$ to obtain the following: 


$$
\left[f^{\prime \prime}\left(t^{*}\right)-(r+\sigma-\theta \sigma) f^{\prime}\left(t^{*}\right)\right] \frac{\partial t^{*}}{\partial \theta}=-\sigma f\left(t^{*}\right)+r\left[1+\frac{\sigma}{\lambda+r}\right] \frac{\partial J_{0}}{\partial \theta}
$$

Since the term in the square brackets on the left-hand side of (7) is negative, $\frac{\partial t^{*}}{\partial \theta}$ has a sign opposite to that of the right-hand side of (7). Applying the envelope theorem to equation (6), we conclude that $\frac{\partial J_{0}}{\partial \theta}=\frac{\sigma \int_{x=0}^{t^{*}} f(x) e^{-(r+\sigma) x} d x}{\left[1-e^{\left.-(r+\sigma) t^{*}\right]\left[1-\frac{\lambda}{(\lambda+r)(\sigma+r)}\right]}\right.}>0$. Intuitively, increasing the compensation rate $\theta$ increases the value of the use right to cleared land since it would increase an owner's receipts even if he did not alter his rotation decisions at all. The value of this compensation (that is, the maximum a farmer would be willing to pay for it) is the increase in the value of the use right $\left(U_{0}\right)$ that this increased compensation rate $(\theta)$ induces.

To determine the effect of an increased probability of compensation on the optimal rotation period, substitute the expression for $d J_{0} / d \theta$ back into (7), and rewrite its right-hand side as $\frac{(r+\sigma) \sigma \int_{x=0}^{t^{*}}\left[f(x)-f\left(t^{*}\right)\right] e^{-(r+\sigma) x} d x}{\left[1-e^{-(r+\sigma) t^{*}}\right]}$. Since $f^{\prime}>0$, $f\left(t^{*}\right)>f(x)$ for $x \in\left[0, t^{*}\right)$, the right-hand side of (7) is negative. Therefore, $\frac{\partial J_{0}}{\partial \theta}>0$ and $\frac{\partial t^{*}}{\partial \theta}>0$. Intuitively, an increase in the expected compensation has no effect on the marginal benefit of waiting a little longer to enhance the net value of the wood volume $\left(f\left(t^{*}\right)\right)$ but lowers the marginal cost of waiting a littler longer $((r+\sigma(1-$ $\theta)) f\left(t^{*}\right)+r\left(1+\frac{\sigma}{\lambda+r}\right) J_{0}$ ). This marginal cost falls because the probability of not getting compensated $(1-\theta)$ falls (the direct effect). ${ }^{14}$ As a result, farmers in

\footnotetext{
${ }^{14}$ Increased probability of compensation does raise the value to the farmer of receiving cleared land but this indirect effect on the marginal cost curve is dominated by the direct effect.
} 
regions where compensation is anticipated to be larger will have lower marginal costs of delaying harvesting and will have longer rotation periods.

The level of this expected compensation turns out to determine the effect of increasing the risk of expropriation $(\sigma)$ on the optimal rotation age $\left(t^{*}\right)$. Reed concluded that an increase in risk always induced the farmer to shorten the rotation period because he assumed that no compensation or insurance benefit would be paid if the farmer lost his trees before harvesting them.

We first show analytically that, for Reed's case where no compensation is paid $(\theta=0)$, the optimal rotation age strictly decreases in $\sigma$; we then provide an example where the optimal rotation age strictly increases with $\sigma$ when compensation is always paid $(\theta=1)$.

Assume that $\theta=0$, equation (5) and (6) reduce to (5') and (6') as follows:

$$
\begin{gathered}
f^{\prime}\left(t^{*}\right)-(r+\sigma) f\left(t^{*}\right)-r\left(1+\frac{\sigma}{\lambda+r}\right) J_{0}=0 \\
J_{0}=\frac{f\left(t^{*}\right) e^{-(r+\sigma) t^{*}}-c}{\left[1-e^{\left.-(r+\sigma) t^{*}\right]\left[1-\frac{\lambda}{(\lambda+r)(\sigma+r)}\right]}\right.}
\end{gathered}
$$

Equation (6') can be further rewritten as $J_{0}=\frac{(r+\sigma)\left[f\left(t^{*}\right) e^{-(r+\sigma) t^{*}}-c\right]}{1-e^{-(r+\sigma) t^{*}}}\left\{\frac{\lambda+r}{r(r+\sigma+\lambda)}\right\}$. By the envelope theorem, $\frac{d J_{0}}{d \sigma}=\left.\frac{\partial J_{0}}{\partial \sigma}\right|_{t^{*}}$. Clearly the factor in braces on the right of the equation defining $J_{0}$ is positive but strictly decreasing in $\sigma$. To show that value of 
land use right strictly decreases as the hazard increases, we need merely verify that the remaining positive factor decreases as well. ${ }^{15}$

To verify that the rotation age $\left(t^{*}\right)$ strictly decreases in $\sigma$, substitute the expression for $J_{0}$ into equation $\left(5^{\prime}\right)$ and simplify to obtain $f^{\prime}\left(t^{*}\right)=\left[f\left(t^{*}\right)-\right.$ $c] \frac{r+\sigma}{1-e^{-(r+\sigma) t^{*}}}$. We can again interpret the left- and right-hand sides of this equation defining $t^{*}$ as marginal benefit and marginal cost, respectively. It is straightforward to show that the marginal-cost curve shifts up uniformly when $\sigma$ increases. ${ }^{16}$ Since the marginal-benefit curve must cut the marginal-cost curve from above at $t^{*}$, we can conclude that a marginal increase in risk will result in a marginal decrease in the optimal rotation age: $\frac{d t^{*}}{d \sigma}<0$.

To demonstrate that Reed's conclusion does not always hold, we provide a counterexample. In this and all future examples, we utilize the three-parameter Chapman-Richards growth function, $f(T)=a b\left(1-e^{-b T}\right)^{d}$ where $f(T)$ denotes the net dollar value to the farmer if the tree were harvested at $\mathrm{T}$ and $a, b, d$ are exogenous parameters. The function, which satisfies our assumptions, is used throughout the comprehensive forestry textbook of Amacher et al. (2009), and has

\footnotetext{
15 Denote this remaining factor as $h(\sigma)=\frac{(r+\sigma)\left[f\left(t^{*}\right) e^{-(r+\sigma) t^{*}}-c\right]}{1-e^{-(r+\sigma) t^{*}}}$. Differentiating and simplifying, we obtain: $\frac{\partial h(\sigma)}{\partial \sigma}=\frac{\left[f\left(t^{*}\right) e^{a}-c\right]\left[1-e^{a}\right]-\left[f\left(t^{*}\right) e^{a}-c e^{a}\right][-a]}{\left[1-e^{a}\right]^{2}}$, where $a=-(r+\sigma) t^{*}<0$, thus $0<e^{a}<1$. Let $g(x)=1+x-e^{x}$. The function has the following properties: (1) $g(0)=0$, and (2) $g^{\prime}(x)=1-e^{x}>0$ for $x<0$, so $g(a)=1+a-$ $e^{a}<0$, i.e. $1-e^{a}<-a$. It is also true that $f\left(t^{*}\right) e^{a}-c<f\left(t^{*}\right) e^{a}-c e^{a}$, since $e^{a}<1$. Thus, the first product in the numerator of the differentiation is less than the second one, and it implies $\frac{\partial h(\sigma)}{\partial \sigma}<0$. Hence, $J_{0}$ strictly decreases in $\sigma$ for any $\sigma, \lambda>0$.

16 Denote the marginal-cost curve, for any $t$, as $[f(t)-c] m(\sigma, t)$, where $m(\sigma, t)$ is defined as $m(\sigma, t)=\frac{r+\sigma}{1-e^{-(r+\sigma) t}}$, $\frac{\partial m}{\partial \sigma}=\frac{1-(1-a) e^{a}}{\left[1-e^{a}\right]^{2}}$ for $a=-(r+\sigma) t<0$. Let $n(a)=1-(1-a) e^{a}$. It can be shown that $n(0)=0$ and $n^{\prime}(a)<0$ for $a<0$. Thus, $n(a)>0$ for $a<0$. Thus, the partial derivative is positive and the marginal-cost curve shifts up at every $t$.
} 
been shown by Sun et al. (1999) to describe well the growth of the Korean pine, one of the most important timber species naturally distributed across China. ${ }^{17}$

Assume $c=6, r=0.05$, and the net value of the stand grows according to the following:

$$
f(t)=640 *[1-\exp (-0.0035 * t)]^{0.6}
$$

Assume that compensation based on the current net value of the expropriated stand is always paid $(\theta=1)$. In Figure 1 , we plot $t^{*}$ and $J_{0}$ against $\sigma$ for this example (computed using MATLAB 2011a). As shown in Figure 1, the optimal rotation age $\left(t^{*}\right)$ has a vertical intercept equal to the Faustmann rotation age $\left(t_{F}\right)$ and strictly increases as the hazard rate $\sigma$ increases. Hence, for every $\sigma>0, t^{*}>t_{F}$. Thus, the conclusion of Reed (1984) that under uncertainty $t^{*}<t_{F}$ need not hold if the farmer is assumed to be compensated for his loss. ${ }^{19}$

17 We lack data from China to estimate the parameters in our model and so our worked examples should be understood as illustrative.

18 This function is a slight modification of Chapman-Richards's basic equation (Sun et al. 1999).

19 Although we have focused on the extremes of unitary compensation $(\theta=1)$ and no compensation $(\theta=0)$ when determining the effect of an increased hazard rate $(\sigma)$ on the optimal rotation age, similar results hold for compensation rate that are in the neighborhood of either of these two extremes since both $t^{*}$ and $J_{0}$ are continuous functions of $\sigma$. 


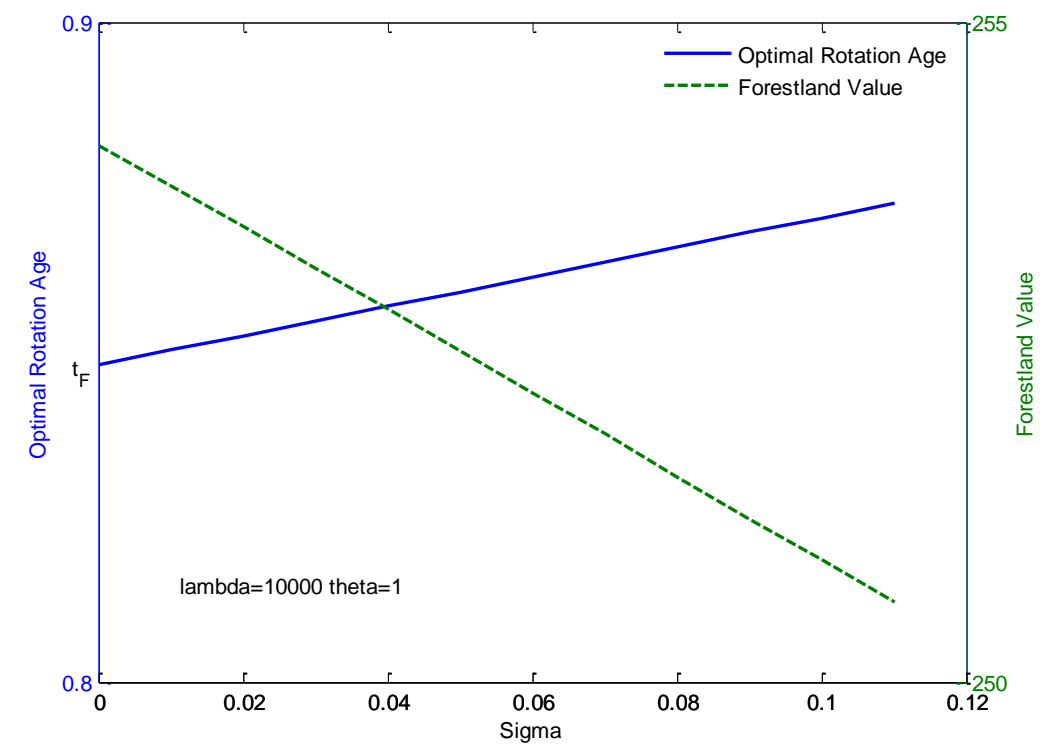

Figure 1. Optimal Rotation Age and Forestland Value with Changing $\sigma$ when Compensation Based on the Current Net Value of the Stand Is Always Paid $(\theta=1)$

\subsection{Full Compensation}

As Figure 1 reflects, even when compensation is always paid $(\theta=1)$, the optimal rotation age still depends on the probability that the farmer loses his trees before he can harvest them. This implies that even $\theta=1$ does not constitute full compensation.

What does constitute "full" compensation? Denote the wealth Faustmann's farmer would obtain in an environment without any risk of expropriations as $J_{F}$ and the chosen rotation age of Faustmann's farmer as $t_{F}$.

Suppose the farmer chooses to cut his stand at some date $t$ and registers his intention with the government. Suppose the government pays compensation if and only if the stand is expropriated prematurely (as $x<t$ ). Suppose in that case, the 
government pays the farmer $\left[f(t)+J_{F}\right] e^{-r(t-x)}-\frac{\lambda}{\lambda+r} J_{F}$ at the time of expropriation. Then, as shown below, the farmer will act as if he faces no risk: regardless of $\lambda, \sigma$, he will plan to cut each stand of trees when it reaches the age of $t_{F}$ years and will earn over an infinite horizon the net expected present value of $J_{F}$.

To see this, note that, given the anticipated compensation, the farmer will choose $t$ to maximize the present value of his expected profit net of costs over the infinite horizon:

$$
\begin{aligned}
W & =\max _{t \geq 0}\left\{\int_{x=0}^{t}\left[\left(\left(f(t)+J_{F}\right) e^{-r(t-x)}-\frac{\lambda}{\lambda+r} J_{F}\right)+\frac{\lambda}{\lambda+r} W\right] e^{-r x} \sigma e^{-\sigma x} d x\right. \\
& \left.+[f(t)+W] e^{-r t} e^{-\sigma t}-c\right\}
\end{aligned}
$$

where $W$ denotes the endogenous private value of forestland. The term in the larger pair of parentheses is the compensation paid at the time of expropriation. The term following this larger pair of parentheses but within the first square brackets is the expected payoff of future income the farmer expects to receive after the use right returns to him. In particular, since the chance that the farmer gets back his land after expropriation follows a Poisson process with a hazard rate of $\lambda$, the expected land value in the environment with oscillating tenure is $\frac{\lambda}{\lambda+r} W\left(=\int_{x=0}^{+\infty} \lambda e^{-\lambda x} W e^{-r x} d x\right)$. Both terms must be discounted back from the date of expropriation to when the trees were planted $x$ years earlier. The second pair of square brackets contains the present value of the payoff if expropriation does not prevent the farmer from harvesting the current crop of trees at the intended age $(t)$. 
From this discounted sum must be deducted the present value cost of planting the stand of trees.

We can rewrite equation (9) as

$$
\begin{aligned}
& W=\max _{t \geq 0}\left(f(t)+J_{F}\right) e^{-r t}\left(1-e^{-\sigma t}\right)+\frac{\lambda}{\lambda+r}\left(W-J_{F}\right) \int_{x=0}^{t} \sigma e^{-(r+\sigma) x} d x+ \\
& {[f(t)+W] e^{-r t} e^{-\sigma t}-c}
\end{aligned}
$$

First note that if one sets $W=J_{F}$ on the right-hand side of equation (10), then the middle term drops out, and the maximand on the right-hand side reduces to $\left(f(t)+J_{F}\right) e^{-r t}-c$. But this is exactly the objective function Faustmann's farmer faces and he maximizes it at $t_{F}$ and earns over an infinite horizon $J_{F}$. But that would be the left-hand side of equation (10). So $W=J_{F}$ does solve this functional equation.

We conclude by showing that it is the unique solution to this equation. To show this, think of equation (10) as a mapping from $W$ on the right to $\mathrm{N}(W)$ on the left. We seek to show that $\frac{d N}{d W} \in(0,1)$.

Differentiating the right-hand side of (10) and using the envelope theorem, we get

$$
\begin{aligned}
\frac{d N}{d W}=e^{-(r+\sigma) t} & \cdot 1+\frac{\lambda}{\lambda+r} \int_{x=0}^{t} \sigma e^{-(r+\sigma) x} d x \\
= & e^{-(r+\sigma) t} \cdot 1+\left(1-e^{-(r+\sigma) t}\right) \frac{\lambda}{(\lambda+r)} \frac{\sigma}{(\sigma+r)}
\end{aligned}
$$


Given the assumed Inada condition on $f(),. t>0$. Hence, $\frac{d N}{d W} \in(0,1)$ since it is a strictly convex combination of two strictly position numbers, the larger of which is 1.

Graphically, the function $N(W)$ crosses the 45 degree line at $W=J_{F}$ with a strictly positive slope strictly less than 1 . If there were a second crossing, the slope would have be at least 1 , which we have shown cannot occur.

Hence, for any $\lambda$ and $\sigma$, a farmer anticipating the receipt of this compensation would maintain the rotation age $t_{F}$ and would expect to earn in net discounted value over the infinite horizon $J_{F}$.

\subsection{A Comparison of Full Compensation to Compensation Based on the Net Value of the Current Stand}

Suppose the farmer receives the full compensation instead of $\theta f(x)$. Then, regardless of $\sigma, \lambda, \theta>0$ and $\theta \leq 1$, the farmer will always be paid more than he would have been paid if compensation was instead $\theta f(x)$. To verify this, consider first the case where $\theta=1$. The present value of the full compensation we proposed is $\left[f(t)+J_{F}\right] e^{-r t}-\frac{\lambda}{\lambda+r} J_{F} e^{-r x} .20$ This exceeds the present value of what the Chinese government pays $\left(f(x) e^{-r x}\right)$ by $g(x)$ where

$$
g(x)=\left[f(t)+J_{F}\right] e^{-r t}-\frac{\lambda}{\lambda+r} J_{F} e^{-r x}-f(x) e^{-r x}
$$

\footnotetext{
${ }^{20}$ In Reed's special case, the present value of full compensation reduces to $\left[f(t)+J_{F}\right] e^{-r t}-J_{F} e^{-r x}$.
} 


$$
=\left[f(t) e^{-r t}-f(x) e^{-r x}\right]+J_{F}\left[e^{-r t}-\frac{\lambda}{\lambda+r} e^{-r x}\right]
$$

It is easy to show that $g(t) \geq 0$ and

$$
g^{\prime}(x)=e^{-r x}\left[r f(x)+\frac{\lambda}{\lambda+r} r J_{F}-f^{\prime}(x)\right]<0
$$

The final inequality holds since the farmer will choose rotation age $t=t_{F}$ and will receive expropriation only if $x \leq t$. Since $g(t) \geq 0$ and $g^{\prime}(x)<0$ for $x \leq t_{F}$, $g(x)>0$. That is $\left[f(t)+J_{F}\right] e^{-r t}-\frac{\lambda}{\lambda+r} J_{F} e^{-r x}$ is strictly greater than $f(x) e^{-r x}$, and farmers are under-compensated when $\theta=1$. Intuitively, the government would be compensating the farmer for taking his stand of trees with its net current value; although this may sound appropriate, these funds will grow more slowly than the asset that has been taken from him would have grown. We now relax our assumption that $\theta=1$. When $\theta<1$, the farmer would be shortchanged even more. Formally, the last term defining $g(x)$ would be replaced by $\theta f(x) e^{-r x}$ and the resulting $g(x)$ would be even larger.

\section{Loss of Forest Value Due to the Uncertain Tenure Policy}

In this section we show how our model can be used to estimate the net gain in forest value that China could potentially achieve if it eliminates altogether the frequent transfers of use rights and instead secures for every farmer the right to grow trees on his parcel in perpetuity. Under the tree growth function we have hypothesized the net value of China's forest output would more than double. This overall change can in turn be decomposed into four parts. If use rights were secure, (1) parcels would no longer remain barren for extended intervals; (2) trees would 
no longer be harvested by the village following the expropriation before the age that would have maximized expected wealth in the insecure environment; and instead (3) each tree would be harvested at an age that would maximize net wealth in a secure environment. Collectively, these three changes (almost entirely due to the first) would cause forest output to approximately double. In addition, it seems likely that (4) farmers would switch from fast growing trees which attain their full volume rapidly (like bamboo) to trees which initially grow slowly but eventually reach a much larger size. Trees of the former type might be best suited for an environment with insecure use rights and trees of the latter type might be best suited for a secure environment. That is why we say that in our example net forest output would more than double.

We do not know what tree type would be chosen if use rights were secure. However, for the purpose of illustrating this last effect, we hypothesize a tree type with the following growth function:

$$
\hat{f}(t)=\left\{\begin{array}{lr}
0 \\
1780 *[1-\exp (-0.0035 *(t-3))]^{0.6} & 0 \leq t \leq 3 \\
t>3
\end{array}\right.
$$

In the insecure environment $(\sigma=0.105, \lambda=0.043)^{21}$, farmers would strictly prefer trees with growth function $f(t)=640 *[1-\exp (-0.0035 * t)]^{0.6}$, but in a secure environment $(\sigma=0, \lambda \rightarrow+\infty)$ they would strictly prefer trees with growth function $\hat{f}(t) .^{22}$

\footnotetext{
21 In the past 65 years, China has undergone three phases of private property regimes $(1950-1955,1981-1986$, and the still ongoing one starting from 2008) and two phases of village property regimes (1956-1980 and 19872007). Thus, the maximum likelihood estimates for the two hazard rates are $2 / 19=0.105$ and $2 / 46=0.043$. This yields expected lengths of the private and village phases of 9.5 years and 23 years, respectively. 22 According to our simulation, when no compensation is involved, the forest value farmers would derive by planting eventually bigger trees under a secure environment (280.3) is higher than that from planting initially fast-growing trees (254.1). However, with forest tenure insecurity, the value derived from planting eventually
} 
In order to evaluate the net gain in forest value that China could potentially achieve if it eliminated altogether the frequent transfers of use rights, we compare the net discounted forest value (denoted $J_{U}$ ) in our model to the net discounted value in the Faustmann model (denoted $J_{F}$ if the same tree type is utilized and $\hat{J}_{F}$ if farmers switch to the new tree type).

$J_{U}$ equals (i) the forestland value $J_{0}$ minus the expected present value of the compensation payments from the government over time plus (ii) the expected present value of the trees expropriated over time (net of costs). Compensation payment should be deducted from the farmer's payoff since, while a benefit to him, they are merely a transfer from others elsewhere in society. ${ }^{23}$ The value of the trees surrendered to the village (net of the cost of harvesting them) should be added back because it represents the part of the value of the forest that was not included in the farmer's payoff $J_{0}$ but is earned by the village.

$J_{U}$ can be calculated with equation (11) below, which is the sum of two terms. The first term (corresponding to (i) above) is the value of $J_{0}$ minus the value of government compensation; the second term (corresponding to (ii) above) is the value of trees surrendered to the government (net of harvesting costs) when it collectivizes the land:

$$
J_{U}=\frac{f\left(t^{*}\right) e^{-(r+\sigma) t^{*}}-c}{\left[1-e^{-(r+\sigma) t^{*}}\right]\left[1-\frac{\lambda}{(\lambda+r)(\sigma+r)}\right]}+\frac{\sigma \int_{x=0}^{t^{*}} f(x) e^{-(r+\sigma) x} d x}{\left[1-e^{-(r+\sigma) t^{*}}\right]\left[1-\frac{\lambda}{(\lambda+r)(\sigma+r)}\right]}
$$

bigger trees (83.3) is lower than that from planting initially fast-growing trees (106.6). Qualitatively similar results hold if the government always compensates losses based on the net value of the expropriated stand. ${ }^{23}$ Although we deduct compensation to the farmer because it is a transfer payment, we continue to assume that the farmer takes compensation into account when choosing the optimal age to cut his trees. 
The two terms have different numerators but the same denominator. The numerator of the first term is strictly positive, since the farmer would at least secure a positive cash flow from forestry operation when he cuts the trees at the optimal age. The numerator of the second term is at least non-negative, since we assumed $f(t) \geq 0$ for any $t \geq 0$. Overall, we estimate that $J_{F} / J_{U} \approx 2$ and $\hat{J}_{F} / J_{U} \approx 2.5$.

This overall gain can be usefully decomposed by dividing it into a series of partial gains in moving from the original situation of policy oscillation depicted in our model to the final situation with complete security and a more suitable tree type depicted in the Faustmann model.

In the first step, we assume that farmers would still harvest trees at $t^{*}$, as determined in the insecure policy situation, but we assume that the moment the villages acquire the use right and chop down the trees, the use right is returned to the farmers. That is, we assume that the time interval during which the parcel is barren shrinks to zero $(\lambda \rightarrow+\infty)$. We define $J_{S}$ as the discounted expected revenue from forestry under this situation:

$$
J_{S}=\frac{f\left(t^{*}\right) e^{-(r+\sigma) t^{*}}-c}{\left[1-e^{-(r+\sigma) t^{*}}\right] \frac{\sigma}{\sigma+r}}+\frac{\sigma \int_{x=0}^{t^{*}} f(x) e^{-(r+\sigma) x} d x}{\left[1-e^{-(r+\sigma) t^{*}}\right] \frac{\sigma}{\sigma+r}}
$$

$J_{S}$ has the same numerator as $J_{U}$, but its denominator is smaller than that of $J_{U}$. Thus, $J_{S}$ is always greater than $J_{U}$.

In the second step, we assume that the village does not clear-cut the trees but immediately relinquishes its use right to the plot. It is as if the farmer never relinquishes the parcel but does not adjust the rotation period. The corresponding forestry value is 


$$
J_{N}=\frac{f\left(t^{*}\right) e^{-r t^{*}}-c}{1-e^{-r t^{*}}}
$$

In the third step, we assume that the farmer adjusts his rotation period from the one appropriate in the oscillating situation to Faustmann's rotation period, but still sticks to the old tree type:

$$
J_{F}=\frac{f\left(t_{F}\right) e^{-r t_{F}-c}}{1-e^{-r t} F} 24
$$

Finally, we assume that, when farmers realize that the property right to use the forestland will henceforth be secure, they will switch to the type of tree best suited to that environment and adjusting the rotation period appropriately, generating maximized net wealth of

$$
\hat{J}_{F}=\frac{\hat{f}\left(\hat{t}_{F}\right) e^{-r \hat{t}_{F}-c}}{1-e^{-r \hat{t}_{F}}}
$$

where $\hat{t}_{F}$ is the optimal rotation age under Faustmann's condition, with regard to the new tree type. We break the overall gain $\hat{J}_{F}-J_{U}$ into four components: $\hat{J}_{F}-J_{U}=\left(J_{S}-J_{U}\right)+\left(J_{N}-J_{S}\right)+\left(J_{F}-J_{N}\right)+\left(\hat{J}_{F}-J_{F}\right)$ and express each component as a percentage of the overall gain. That is $G_{1}=\frac{J_{S}-J_{U}}{\hat{J}_{F}-J_{U}} * 100, G_{2}=\frac{J_{N}-J_{S}}{\hat{J}_{F}-J_{U}} * 100$, $G_{3}=\frac{J_{F}-J_{N}}{\hat{J}_{F}-J_{U}} * 100, G_{4}=\frac{\hat{J}_{F}-J_{F}}{\hat{J}_{F}-J_{U}} * 100$. Note that $G_{1}+G_{2}+G_{3}+G_{4}=100$.

This decomposition helps determine the importance to the overall gain of each of the four sources of change. $G_{1}$ represents the percentage of the overall gain that would occur ceteris paribus if the land was returned to the farmer immediately after the village cleared it of trees. $G_{2}$ represents the percentage of the overall gain that would occur ceteris paribus if in addition the village did not clear cut the trees (or

\footnotetext{
24 Faustmann's model is a special case of ours. Hence, $J_{F}$ in equation (14) is a special case of $J_{0}$ defined in equation (6) and is obtained by setting $\sigma=0$ and $\lambda \rightarrow+\infty$. Similarly, $t_{F}$ in equation (14) is the special case of $t^{*}$ defined in equation (5) and is obtained by setting $\sigma=0$ and $\lambda \rightarrow+\infty$.
} 
equivalently, the farmer never relinquished the use right). $G_{3}$ represents the percentage of the overall gain that would occur ceteris paribus if in addition the farmer adjusted his cutting time because land tenure has become secure. $G_{4}$ represents the percentage of the overall gain that would occur ceteris paribus if in addition farmers switched to a new tree type that is more suitable under secure land tenure and then adjusted the harvesting age optimally.

We use the illustrative tree growth function $f(t)$ described in Section 3.1 to estimate the first three sources of gain and the growth function $\hat{f}(t)$ to illustrate the last source of gain. We will assume the interest rate as $5 \%$ and set $\lambda=1 / 23$, which corresponds to the average lengths of the village property phases as suggested by our examination of China's forest tenure history. We examine how the component gains change as the hazard rate $\sigma$ varies with no compensation $(\theta=0)$ and with a unitary compensation rate $(\theta=1)$, respectively.

Figure 2 and 3 plot against the expropriation rate $(\sigma)$ the decomposition of the predicted percentage gain in forest value from securing the farmer's use right. As shown in the figures, when the government either does not pay compensation when expropriating forestland or compensates that loss based on the net value of the expropriated stand, the orders of importance of these partial gains are quite similar. Most of the gain (almost 80\%) could be secured if the government could return the land to the farmers immediately after clear-cutting (see the line of $G_{1}$ evaluated at $\sigma=0.105)$. Compared with that, the gain from switching to a tree type more suitable to an environment with secure property rights is less important. This accounts for approximately $20 \%$ (see the line of $G_{4}$ evaluated at $\sigma=0.105$ ). The 
gains resulted from eliminating clear-cutting of forests under the village property regime (see the line of $G_{2}$ evaluated at $\sigma=0.105$ ) and correcting the rotation age (see the line of $G_{3}$ evaluated at $\sigma=0.105$ ) are quite minor, and almost negligible.

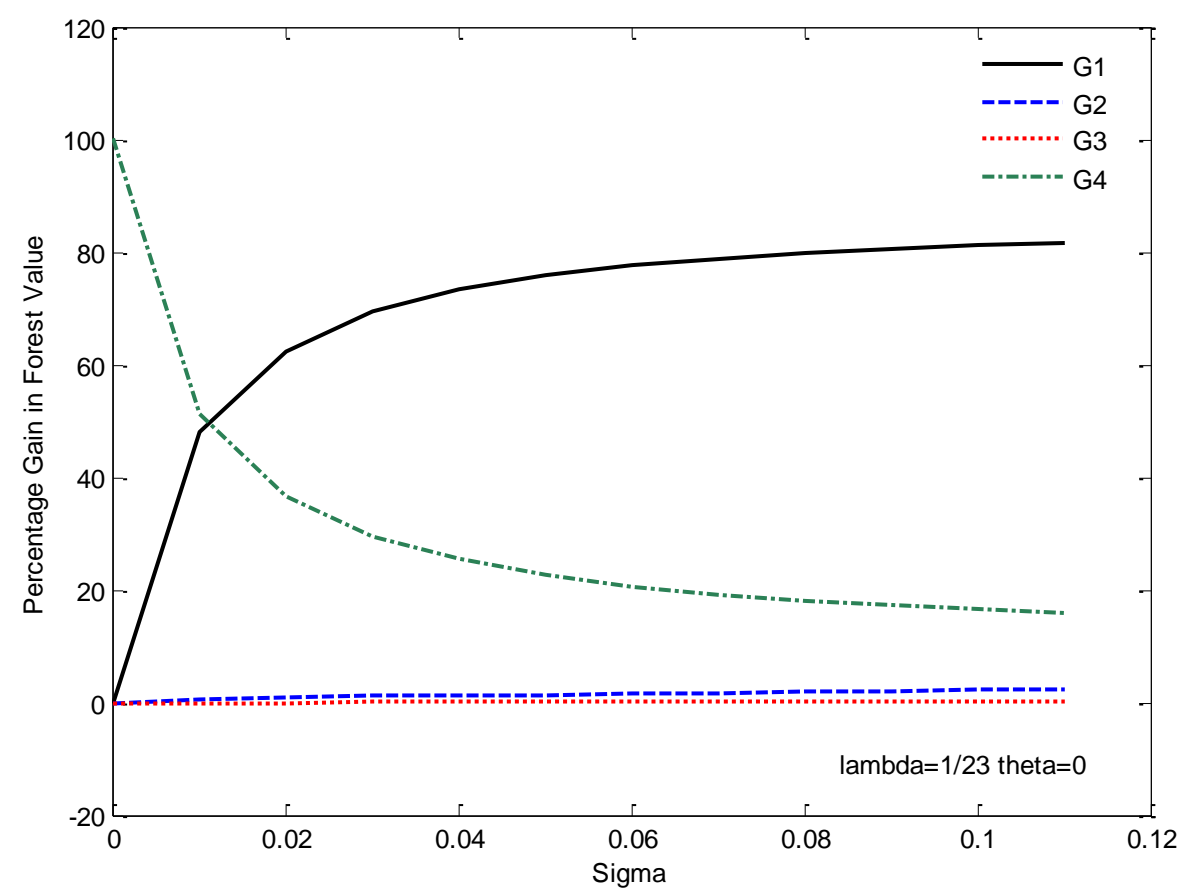

Figure 2. Percentage Decomposition of Gain in Forest Value from Securing Use

$$
\text { Right }(\theta=0)
$$




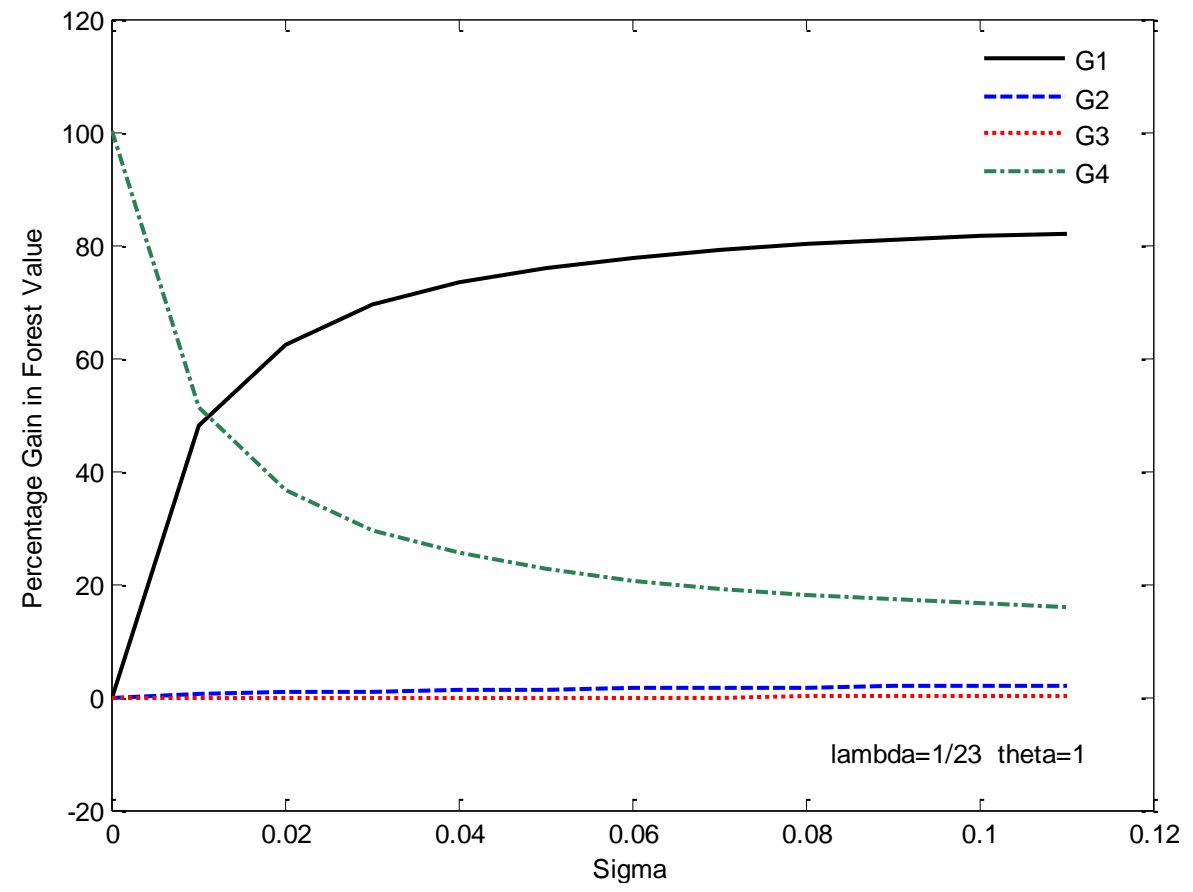

Figure 3. Percentage Decomposition of Gain in Forest Value from Securing Use

$$
\text { Right }(\theta=1)
$$

Securing individual property rights is a necessary step for China if the country is to realize its goal of expanding domestic forest production and alleviating its dependence on timber imports. As Yin and Xu [2002] have argued "It must be recognized that any political instability or policy uncertainty could cause the resource base to shrink...one may also wonder why few efforts have so far been directed to addressing the institutional impediments to forestry growth in the south, which has great potential for not only timber production but also ecological services [p. 1765].

There are encouraging signs that use rights are becoming more secure. In 2008, the State Council of China, along with the central committee of the Communist part, launched a tenure reform in the collective forest sector. Scholars generally believe 
that, compared to the first round of privatization in the 1980s, this second round is more likely to achieve the goal of securing long-term private use rights over forests. Under this reform, the process of decision-making in forest villages has been made much more democratic; a two-thirds majority of forest farmers is now required before changes in tenure arrangements can be adopted. No such rule existed in the first round of privatization. Second, the lease of forest use rights is now 70 years long, whereas in the first round of privatization, it was less than 20 years. Whether these reforms are permanent or just another passing phase remains to be seen. ${ }^{25}$

\section{Conclusion}

This paper provides a framework for assessing the effects on forest output of the stochastic oscillations between private and village property regimes that have occurred in China during the past 65 years. The induced policy uncertainty distorts the harvesting decisions of farmers holding use rights to the land. By our reckoning, the losses in forest output resulting from this uncertainty appear large. Understanding the consequences of this policy-induced uncertainty is particularly important at a time when China is engaged in the most ambitious reforestation efforts in the developing world in the hope of significantly increasing its domestic supply of timber.

In the special case where the expected time spent in the village property regime approaches zero, our model can be interpreted as one where harvesting occurs under the threat of a catastrophic event like a forest fire and where the government compensation is reinterpreted as the payout from insurance against the

\footnotetext{
25 Surveys conducted in 2011 (Yu, 2013 p. 179) still reveal widespread skepticism among farmers that the 2008 reforms will protect their long-term investments in forestry.
} 
catastrophe. We show, the conclusion of Reed (1984) and others that increased risk of forest fire inevitably motivates farmers to harvest earlier fails to hold if compensation is based only on the net value of the current stand at the time of the loss. We show, however, that this would not fully compensate farmers for their loss. If farmers were fully compensated for the uncertainty that they faced, they would behave like Faustmann's foresters in a riskless environment. 


\section{Appendix I: the History of Oscillating Use Rights}

During the last 65 years, tenure of nonstate forests has oscillated between the two regimes of private and village property. There have been at least four radical transitions, with no regime lasting more than 25 years.

\section{Private landownership resulting from the Land Reform Campaign (1950-} 1955)

Before 1950, feudal landownership dominated most of China. Forestland was either village property or was owned by landlords or rich peasants. The 1950 Land Reform Campaign radically changed the ownership structure. The newly founded government confiscated most private forestland, nationalized some of it, and distributed the rest to rural households in equal shares (Xu et al. 2004). Private ownership lasted for about three years before China's socialism process began to erode it. The erosion started during 1953-1955, when elementary cooperatives were established and rural households were encouraged to pool their forestland and other means of production. Yet this challenge was relatively insignificant, since less than $60 \%$ of rural households joined elementary cooperatives, and even the participating households still maintained private ownership of their land (Liu 2001). Thus, before 1955, China's nonstate forests were governed by a newly established, unstable private regime.

\section{Collectivization with the socialism campaign (1956-1980)}

As the socialism campaign proceeded to the advanced cooperative period in 1956, private ownership of forestland was terminated. Under this new regime, forestland, like other means of production, was expropriated. It became the 
collective property of advanced cooperatives (Walker 1966; Liu 2001). Whether Chairman Mao coerced or stimulated farmers to join the collectivization campaign is unclear, but by the end of $1956,96 \%$ of rural households were incorporated in advanced cooperatives. Although a village collective regime dominated this period, there still remained some respect for farmers' ownership of land. First, when rural households joined an advanced cooperative, they were compensated in monetary terms for the value of their forests. Second, they continued to own non-timber trees on small spots of land (Liu 2001).

Collectivization of property rights over land peaked during the people's commune period, starting in early 1958 . While previously an elementary cooperative had typically consisted of 25 rural households and an advanced cooperative 500 households, the average size of a people's commune sharply increased to 4,800 households. In addition, the village collective regime further expanded to cover the non-timber trees that had been privately owned in the advanced cooperative period (Xu et al. 2004).

Accompanying this over ambitious collectivization was a fanatical social campaign, the Great Leap Forward. Around the end of 1957, China resolved to catch up to Britain in terms of its industrialization level, with the production of steel as a core symbol. Beginning in early 1958, collective communes clear-cut forests regardless of age in an over zealous attempt to fuel laggard steel furnaces. Little consideration was given to the ecological and economic costs of tree cutting (Wang et al. 2007). As a result, in Hubei Province, to name one example, forest area and volume decreased by $30 \%$ during this period (Liu 2001). The Great Leap Forward 
campaign, along with the radical ownership transformation in the people's

communes, has been blamed as the major cause of large-scale deforestation that occurred around 1960.

An even more serious consequence of the Great Leap Forward was the Great Famine from 1959 to 1961, which resulted in more than 15 million deaths and great social instability (Peng 1987). In response to this tragedy, the government readjusted the distribution of landownership in rural China in the early 1960s. It returned land property rights and management to lower-level collectives, including both elementary and advanced cooperatives. Non-timber trees and trees planted by households around their homesteads were even returned to individual households (Xu et al. 2004; Liu 2001).

However, the Cultural Revolution (1966-1976) put an end to this short-lived backsliding toward decentralization. This movement asserted on ideological grounds that all properties in a socialist society should be collectively owned. Hence, forestland, including the land that had been returned to individual households, was once again expropriated-this time without proper compensation (Ho 2006).

Overall, the period from 1956 to the early 1980s saw the emergence and dominance of a collective property regime in the forestry sector, with various levels of centralization. This paralleled the trials of land institution design in the early stage of the People's Republic of China (PRC) and involved both rational and irrational policy elements.

\section{Privatization following the "Three Fix" policy (1981-1986)}


After 25 years of inefficient forest operations, the Forestry Department modified the village collective regime, beginning with the release of the Decision on the Issues of Forest Conservation and Forestry Development by the State Council in March 1981. This document "marked the beginning of a long legislative and policy process aimed at encouraging private sector participation by providing increasingly secure resource rights" (Xu et al. 2004, pp.67). The document stipulated that (1) forest resources with clear and non-disputable ownership should be returned to their original owners; (2) plots of forestland, including waste hillsides, riverbanks, and beaches, should be allocated with an egalitarian principle to farmers for long-term sustainable operation; and (3) trees planted on individual homesteads and family plots should be private property. In Chinese, this policy is called linye sanding, or "Three Fix" in forestry.

Under this system, nonstate forestland was still collectively owned, but rural households were entitled to full property rights of forest resources as well as the right to use the land. In addition, as with privatization in the 1950s, the new round of privatization in the 1980s also emphasized the principle of equal distribution of forestland. Given that the registered rural population had remained stable from the 1950s to the 1980s, farmers got back roughly an equal share of forestland, although not always their original land or land of exactly the same value.

\section{Recurrence of a village property regime (1987-2007)}

The purpose of establishing a private property regime in forestry was to improve the management of existing forests and to encourage private investment in new plantations. However, such goals had hardly been realized previously, 
especially in the southern regions of nonstate forest. Farmers were therefore skeptical that the privatization policy would last. So instead of expanding activities of reforestation and forest management, the farmers exploited the forest resources they had been given (Liu 2001).

The resulting deforestation once again undermined the government's confidence in the effectiveness of the private regime in governing the forestry sector (Yin and Newman 1997). So in 1987, the central government terminated the privatization reform. Accordingly, many local governments in the southern regions restored collective management of forestland that had been contracted to households (Liu 2001). Unlike the first round of collectivization in 1956, this time the collectivization did not involve redistribution of property rights, at least nominally, but only centralization of decision-making rights over the forestland that had already been property of the village collective. Although the government did not pay out direct compensation, it did promise to share forestry revenues in village collectives with participating households. In addition, the 1987 collectivization occurred in a relatively stable political environment without significant influence from irrational social campaigns, and thus no serious clear-cutting accompanied this round of collectivization.

\section{The new round of privatization (2008-?)}

For the next 16 years, a relatively stable village property regime dominated the nonstate forest sector, until privatization reform was initiated once again in some regions in 2003 (Xu et al. 2008). With the aim of increasing forestry productivity, the government once again decided to allocate use rights of forestland to individual 
households. Like the previous privatization reforms, this newest round of privatization also emphasizes farmers' equal rights of contracting forestland. In addition, it addresses farmers' concern about uncertainty regarding future forestry policy by stipulating that forestland contracts last for 70 years and that the contracts are renewable, inheritable, and transferrable (SFA 2008). This privatization reform was expanded to a national scale in 2008 and is still ongoing. Its effects on nonstate forest operation await further evaluation.

\section{Appendix II: Comparative Statics}

To supplement the comparative statics results reported in Section 3.1, we determine the effects of increasing the probability that the use right is returned to the farmer $(\lambda)$. Substitute $J_{0}$, as expressed in equation (6), into equation (5) to obtain the following:

$f^{\prime}\left(t^{*}\right)=(r+\sigma-\theta \sigma) f\left(t^{*}\right)+\frac{(r+\sigma)\left[f\left(t^{*}\right) e^{-(r+\sigma) t^{*}}-c+\sigma \theta \int_{x=0}^{t^{*}} f(x) e^{-(r+\sigma) x} d x\right]}{\left[1-e^{\left.-(r+\sigma) t^{*}\right]}\right.}$.

This equation implicitly defines $t^{*}$ in terms of exogenous parameters. Since $\lambda$ does not appear in this equation, the optimal rotation age is unaffected by changes in $\lambda$ for any admissible $\theta$ and $\sigma$. Thus, $\frac{\partial t *}{\partial \lambda}=0$.

An exogenous increase in $\lambda$ does, however, increase the value to the farmer of the use right to cleared land $\left(U_{0}\right)$. Intuitively, shortening the expected time the use right is held by the village $(1 / \lambda)$ raises the private value of the use right to cleared land. More formally, both the numerator and denominator of equation (6) are 
positive. While an increase in $\lambda$ has no effect on the former, it does reduce the latter. Thus, $\frac{\partial J_{0}}{\partial \lambda}>0$.

\section{Appendix III: Sensitivity to Assumed Village Harvesting Rule}

\section{Introduction}

In the text, we assumed that when a farmer regained the use of his parcel he typically found it stripped of trees. In reality, however, farmers sometimes found trees growing on their parcels when they regained their use rights. Therefore, we assume here that, if the village retains the use right, it harvests the trees when they reach exogenous age $a_{c}$. Hence, if the farmer regains the use right before they reach age $a_{c}$, the parcel is returned with trees on it; otherwise it is stripped of trees. Our goal here is to show the sensitivity of our calculation of losses due to insecure property rights to changes in our assumption about village harvesting behavior.

Since this analysis is inherently more complicated, we conduct it in discrete time. We then approximate continuous time in our simulations by letting period lengths shrink to one day. Just prior to the table on p. 46 reporting our sensitivity results, we verify that our results in this more general model match those in the text for the special case where the villages harvest trees if they are at least 1-day old.

\section{The Model}

Suppose, trees on the parcel are age $a$ and the use right belongs to the village. If the trees are at least $a_{c}$ years old, then the village harvests the trees and does not replant. Otherwise, it waits for the trees to reach that age before harvesting them. At 
the beginning of the next period, therefore, the parcel is either bare or has trees on it of age $a+1$. Moreover the village may retain the use right to harvest trees or the farmer may have acquired it. If the village continues to hold the use right then it will chop down the trees if and only if $a+1=a_{c}$. If the farmer gains the use right and the parcel has no trees on it, he plants and waits until the next period. If the parcel does have trees on it, he harvests them and immediately replants if and only if doing so maximizes his expected net wealth. In that case, the trees would be 1-year old in the next period.

We denote the discrete-time counterparts to $r, \sigma$, and $\lambda$ with a circumflex over each variable. Thus, $\hat{r}=e^{r}-1, \hat{\sigma}=1-e^{-\sigma}, \hat{\lambda}=1-e^{-\lambda}$. As in the text, we denote by $J_{a}$ the wealth the farmer expects if he currently holds the use right and the trees on the parcel are $a$ years old. We denote by $V_{a}$ the wealth the farmer expects if the village currently holds the use right and the trees on the parcel are $a$ years old. The latter wealth comes from the immediate compensation for expropriation and from expected future receipts.

Only the farmer plants and he incurs a cost $c$ when he plants. Every tree is eventually harvested. To avoid omitting a planting cost or counting one twice, we adopt the following convention: we charge the farmer for the planting cost at the time the tree is harvested regardless of whether the farmer or the village harvests the tree. Thus if a tree of age $a$ is harvested by either agent, the farmer incurs a planting cost then of $c(1+\hat{r})^{a}$.

If a farmer has the use right to the land and it contains a tree of age $a$, then he can cut it immediately, 1 period later (when it is $a+1$ years old) or 2 periods later 
(when it is $a+2$ years old)..---assuming in each case that he still has the use right. What is the expected payoff if he chooses to cut his $a$-year old trees after $t$ more years where $t=0,1,2, \ldots$ and immediately replants?

There are two possibilities: either he retains the use right $t$ years later, or he loses it in the interim. In the former case, he cuts the tree and re-plants immediately. He thus gets $f(a+t)-c(1+\hat{r})^{a+t}$ when he cuts and replants plus, in expectation, $\frac{(1-\widehat{\sigma}) J_{1}+\widehat{\sigma} V_{1}}{1+\hat{r}}$ from the next period onward---all expressed in dollars at the time the tree is cut. Hence, in terms of dollars when the tree was age $a$, he gets $[f(a+t)-$ $\left.c(1+\hat{r})^{a+t}+\frac{(1-\widehat{\sigma}) J_{1}+\widehat{\sigma} V_{1}}{1+\hat{r}}\right] /(1+\hat{r})^{t}$. This happens with probability $(1-\hat{\sigma})^{t}$. If, however, the use right has transited to the village collective after $x(x=1,2, \ldots, t-$ 1) years, then he gets $V_{a+x}$ at the time he regains access to the parcel, which has the value $V_{a+x} /(1+\hat{r})^{x}$ when the trees were age $a$. The probability of his losing his use right after $x$ periods is $\hat{\sigma}(1-\hat{\sigma})^{x-1}$. Putting this all together, we get the following equation for $a=1, \ldots, a_{c}{ }^{26}$

$$
\begin{aligned}
J_{a}= & \max _{t=0,1, \ldots .}\left[f(a+t)-c(1+\hat{r})^{a+t}+J_{0}\right]\left(\frac{1-\widehat{\sigma}}{1+\hat{r}}\right)^{t}+\sum_{x=1}^{t} V_{a+x} \hat{\sigma} \frac{(1-\widehat{-})^{x-1}}{(1+\hat{r})^{x}}(\text { AIII.1 })^{27} \\
& \text { where } J_{0}=\frac{(1-\widehat{\sigma}) J_{1}+\widehat{\sigma} V_{1}}{1+\hat{r}} \quad \text { (AIII.2) }
\end{aligned}
$$

To evaluate AIII.1, we will need expressions for $V_{k}$, for $k=a+1, \ldots, a+t$. But even without this, the equation can be used to determine the net worth from forestry if property rights had been secure. If we set $\hat{\sigma}=0$ the formula reduces to:

\footnotetext{
${ }^{26}$ When the farmer gets the use right back from the village, the parcel will never have on it a tree strictly older than $a_{c}$, since any strictly older tree would have been cut down. Hence, in evaluating $J_{a}$, we need consider only $a=1, \ldots, a_{c}$.

${ }^{27}$ Note: if $t=0$ the sum in the second term is defined to be 0 .
} 
$J_{a}^{F}=\max _{t}\left[f(a+t)-c(1+\hat{r})^{a+t}+\frac{J_{1}^{F}}{1+\hat{r}}\right]\left(\frac{1}{1+\hat{r}}\right)^{t}$

where the superscript $F$ denotes Faustmann's special case $(\hat{\sigma}=0)$ and $a=1,2, \ldots$ To evaluate this expression, we first find $J_{1}^{F}$ by setting $a=1$ and solving for the fixed point. It is then straightforward to set $a=2,3, \ldots$ and to repeat in each case the maximization so that we obtain $\left\{J_{a}^{F}\right\}$ for $a=1,2, \ldots$. We will need this Faustmann benchmark when assessing the losses from insecure property rights.

To evaluate the net wealth from forestry when property rights are insecure $(\hat{\sigma}>0)$, we must obtain an expression for the value to the farmer if the use right passes to the village with trees on it of age $k: V_{k}$. There are two cases to consider:

Case 1: $k=a_{c}, a_{c}+1, \ldots$

If $k \geq a_{c}$ then the village cuts the trees down immediately. The farmer receives compensation $\theta f(k)$ from which must be deducted the capitalized planting cost $c(1+\hat{r})^{k}$. The farmer may later regain his parcel (albeit stripped of trees) $y$ $(=1,2, \ldots)$ periods later and immediately replants. For each dollar received at the random time he replants, its expected value discounted back to the time he received compensation for the previous loss of his use right would equal $\sum_{y=1}^{\infty} \frac{\widehat{\lambda}(1-\widehat{\lambda})^{y-1}}{(1+\hat{r})^{y}}=$ $\left[\frac{\widehat{\lambda}}{\hat{r}+\grave{\lambda}}\right]$. But the farmer doesn't just receive $\$ 1$ at this random time. Whenever the transition back to the farmer does occur, the first thing the farmer will do is to plant and then wait one period so (discounted to the time he plants) he receives $\frac{(1-\widehat{\sigma}) J_{1}+\widehat{\sigma} V_{1}}{1+\hat{r}}=J_{0}$. Hence, discounted to the time the farmer received compensation for his previous loss, his future payoff when the village acquires the use right and the parcel has $k$-year old trees on it is $V_{k}$ where 
$V_{k}=\theta f(k)-c(1+\hat{r})^{k}+J_{0}\left[\frac{\hat{\lambda}}{\hat{r}+\hat{\lambda}}\right]$

AIII.3

Case 2: $k=1,2, \ldots, a_{c}-1$

On the other hand, if when the village gains the use right the trees on the parcel are young $\left(k<a_{c}\right)$, then the village will not harvest them immediately. If the use right returns to the farmer after $y$ years, then for $y=1, \ldots, a_{c}-k$ the parcel will have trees on it of age $k+y$ which would then be worth $J_{k+y}$ to the farmer and hence would be worth $J_{k+y} /(1+\hat{r})^{y}$ discounted back to when the village acquired the use right and the trees were $k$ years old. A transition back to the farmer after exactly $y$ years occurs with probability $\hat{\lambda}(1-\hat{\lambda})^{y-1}$. If the use right returns to the farmer after $y$ years, then for $y \geq a_{c}+1-k$, the trees will be cut and so the farmer gets $J_{0}$ when the parcel is returned to him. We conclude therefore that for $k<a_{c}$ :

$V_{k}=\theta f(k)+\sum_{y=1}^{a_{c}-k} J_{k+y} \frac{\widehat{\lambda}(1-\widehat{\lambda})^{y-1}}{(1+\hat{r})^{y}}+\sum_{y=a_{c}+1-k}^{\infty}\left[J_{0}-c(1+\hat{r})^{y+k}\right] \frac{\widehat{\lambda}(1-\widehat{\lambda})^{y-1}}{(1+\hat{r})^{y}}$ AIII.4

To solve this system, we start with values "guessed" with the help of the Faustmann solution. In particular we let $V_{k}=J_{k}^{F}$ for $k=1,2, \ldots$ and $J_{0}=J_{1}^{F} /(1+\hat{r})$. We then use these to calculate new $J$ 's from AIII.1 and new $V^{\prime} s$ from AIII.3 and AIII.4. We also calculate a new value for $J_{0}$ from AIII.2. The new $V_{k}{ }^{\prime} s$ and new $J_{0}$ then replace the guess based on Faustmann and we again use AIII.1 to compute new $J^{\prime} s$, AIII.3 and AIII.4 to compute new $V^{\prime} s$ and AIII.2 to compute a new $J_{0}$ until convergence is achieved. The code for this model is posted on the JEEM website.

\section{Sensitivity Analysis}

In the continuous-time model in the text, the time unit used for the interests rate, stochastic parameters and tree age is years. The corresponding discrete-time 
model with the time unit in years would have Chapman-Richards parameters a=3.2, $\mathrm{b}=200, \mathrm{~d}=.6$; interest rate $\hat{r}=e^{0.05}-1$; and stochastic parameters $\hat{\sigma}=1-e^{-0.105}$, $\hat{\lambda}=1-e^{-1 / 23}$.

However, that model will differ from the one in the text since the decision maker would be constrained not to act within the course of each year. To more closely approximate the continuous-time model in the text, therefore, we assumed the time unit in the discrete-time model is days (1/365 of a year). Thus, the timerelated parameters are updated as follows: $\hat{r}=e^{0.05 / 365}-1, \hat{\sigma}=1-e^{-0.105 / 365}$, and $\hat{\lambda}=1-e^{-1 /(23 * 365)}$. Finally, if the continuous time growth function $f(1)$ represents one year's growth, then $g(1)=f(1 / 365)$ represents one day's growth. So we use $g(t)=f(t / 365)$ as the growth function in the discrete-time model with the time unit in days. ${ }^{28}$

If we assume that the exogenous harvesting rule of the village collective is to harvest trees which are 1-day old or older, this discrete-time model generates virtually the same results as those in the text where the village is assumed to harvest the trees immediately. In the continuous-time model, the maximized wealth of a tree-cutter in the certain environment envisioned by Faustmann is $J_{F}=$ 314.2924 which is $\frac{J_{F}}{J_{U}}=2.1427$ as large as the maximized wealth in the uncertain environment where use rights switch back and forth between farmer and village. In the special case where the village harvests trees 1-day or older, our simulation of

\footnotetext{
${ }^{28}$ In the illustrative simulations reported in the table below, we set the planting cost at $\mathrm{c}=6$ and assumed no compensation. In case a reader wants to explore the consequences of assuming alternative parameter values, we have deposited the MATLAB code used to generate these simulations on the JEEM website.
} 
the discrete-time model yield virtually the same results: $J_{F}=314.2922$, and $\frac{J_{F}}{J_{U}}=2.1499$.

Having verified this, we can now investigate the sensitivity of our illustrative simulations in the text to relaxation of our assumption there about the village harvesting rule.

We report the results of this investigation in the table below.

\section{Sensitivity of Gain from Securing Property Rights to Changes in Village Harvesting Rule}

\begin{tabular}{ll}
\hline Exogenous Harvesting Rule (days) & $J_{F} / J_{U}$ \\
\hline$a_{c}=1$ & 2.150 \\
$a_{c}=1+365^{\star} 1$ & 3.536 \\
$a_{c}=1+365^{\star} 2$ & 2.966 \\
$a_{c}=1+365^{\star} 3$ & 2.609 \\
$a_{c}=1+365^{\star} 4$ & 2.391 \\
$a_{c}=1+365^{\star} 5$ & 2.247 \\
$a_{c}=1+365^{\star} 6$ & 2.147 \\
$a_{c}=1+365^{\star} 7$ & 2.075 \\
$a_{c}=1+365^{\star} 8$ & 2.024 \\
$a_{c}=1+365^{\star} 9$ & 1.994 \\
$a_{c}=1+365^{\star} 10$ & 1.966 \\
$a_{c}=1+365^{\star} 11$ & 1.952 \\
$a_{c}=1+365^{\star} 12$ & 1.937 \\
$a_{c}=1+365^{\star} 14$ & 1.931 \\
$a_{c}=1+365^{\star} 16$ & 1.939 \\
$a_{c}=1+365^{\star} 18$ & 1.950 \\
$a_{c}=1+365^{\star} 20$ & 1.966 \\
\hline
\end{tabular}


As the village harvesting rule increases, the gain from securing property rights falls at first (as the maximized wealth under insecure property rights rises), reaches a minimum $\left(\frac{J_{F}}{J_{U}}=1.931\right)$ when the village rule is to harvest 14 -year old trees, and then begins to rise. Hence, the advantage of securing property rights is as much as $10 \%$ smaller $\left(\frac{J_{F}}{J_{U}}=1.931\right)$ than we calculated on p. 29 in the text, where we assumed that the village harvests trees at the first opportunity. 


\section{References}

Amacher, G. S., E. Koskela, and M. Ollikainen. 2009. Deforestation and Land Use under Insecure Property Rights. Environment and Development Economics 14(3): 281-303.

Amacher, G. S., M. Ollikainen, and E. Koskela. 2009. Economics of Forest Resources. Boston: The MIT Press.

Bahel, E. 2011. Optimal Management of Strategic Reserves of Non-renewable Natural Resources. Journal of Environmental Economics and Management 61(3): 267-280.

Bennett, M. 2008. China's Sloping Land Conversion Program: Institutional Innovation or Business as Usual? Ecological Economics 65: 699-711.

Bergstrom, C., G. Loury, and M. Persson, M. 1985. Embargo Threats and the Management of Emergency Reserves. Journal of Political Economy 93(1): 26-42.

Cheng, Y. 2004. Studies on Woodland Property Rights Institution of Southern Collective Forest Zone. Beijing: China Forestry Press.

Cox, D. R. 1967. Renewal Theory. London: Science Paperbacks and Methuen \& Co.

Creti, A., and B. Villeneuve. 2013. Commodity Storage with Durable Shocks: A Simple Markovian Model. Mathematics and Financial Economics, 1-24.

Demurger, S., Y. Hou, and W. Yang.2009. Forest Management Policies and Resource Balance in China: An Assessment of the Current Situation. Journal of Environment and Development 18(1): 17-41.

http://jed.sagepub.com/content/18/1/17.full.pdf. 
FAO (Food and Agriculture Organization of the United Nations). 2010.Global Forest Resources Assessment 2010, main report. Rome, Italy.

- - . 2012. Forest Product Consumption and Production.

www.fao.org/forestry/statistics/80938@180723/en/.

Faustmann, M. 1849. Calculation of the Value which Forest Land and Immature Stands Possesses for Forestry. In Martin Faustmann and the Evolution of Discounted Cash Flow, translated by W. Linnard (1968). Oxford: Commonwealth Forest Institute, 42.

Gaudet, G., and P. Lasserre. 2011. The Efficient Use of Multiple Sources of a Nonrenewable Resource under Supply Cost Uncertainty. International Economic Review 52(1): 245-258.

Haight, G. H., W. D. Smith, and T. J. Straka. 1995. Hurricanes and the Economics of Loblolly Pine Plantations. Forest Science 41(4): 675-688.

Hardin, G. 1968. The Tragedy of the Commons. Science 162: 1243-8.

Ho, P. 2006. Credibility of Institutions: Forestry, Social Conflict and Titling in China. Land Use Policy 23(4): 588-603.

Liu, D. 2001. Tenure and Management of Non-state Forests in China since 1950: A Historical Review. Environmental History 6(2): 239-263.

Long, N. V. 1975. Resource Extraction under the Uncertainty about Possible Nationalization. Journal of Economic Theory 10: 42-53.

Ostrom, E. 1990. Governing the Commons. New York: Cambridge University Press. 
Peng, X. 1987. Demographic Consequences of the Great Leap Forward in China's Provinces. Population and Development Review 13(4): 639-670.

Qin, P., F. Carlsson, and J. Xu. 2011. Forest Tenure Reform in China: A Choice Experiment on Farmers' Property Rights Preference. Land Economics 87(3): 473487.

Reed, W. J. 1984.The Effects of the Risk of Fire on the Optimal Rotation of a Forest. Journal of Environmental Economics and Management 11: 180-190.

Routledge, R. D. 1987.The Impact of Soil Degradation on the Expected Present Net Worth of Future Timber Harvests. Forest Science 33(4): 823-834.

SFA (State Forestry Administration). 2008. Suggestions on National Forest Tenure Reform.www.forestry.gov.cn/Zhuanti/content_lqgg/206889.html.

———. 2010. National Forest Resources Inventory, 2004-2008. www.forestry.gov.cn/main/65/content-326341.html.

Song, Y., G. Wang, W. R. Burch, and M. A. Rechlin. 2004. From Innovation to Adaptation: Lessons from 20 Years of the SHIFT Forest Management System in Sanming, China. Forest Ecology and Management 191: 225-238.

Sun, Y., S. Li, H. Cui, C. Li, P. Liu, and J. Zhang. 1999. Growth Models and Site Index Table of Natural Korean Pine Forests. Journal of Forestry Research 10(3): 236-238.

Walker, K. R. 1966.Collectivisation in Retrospect: The "Socialist High Tide" of Autumn 1955-Spring 1956. China Quarterly 26: 1-43.

Wang, S., J. Chen, W. Ju, X. Feng, M. Chen, P. Chen, and G. Yu. 2007. Carbon Sinks and Sources in China's Forests during 1901-2001. Journal of Environmental Management 85(3): 524-537. 
Wen, T., X. Kong, F. Zheng, and X. Cui. 2010. China's Forest Tenure Reform:

Dilemma and Solutions. Hubei, China: Huazhong University of Science and Technology Press. (In Chinese.)

$\mathrm{Xu}$, J., N. Li, and Y. Cao. 2004. Impact of Incentives on the Development of Forest Plantation Resources in China. In What Does It Take? The Role of Incentives in Forest Plantation Development in the Asia-Pacific Region. Paper presented at the UNFF Intersessional Experts Meeting on the Role of Planted Forests in Sustainable Forest Management, 59-79.

Xu, J., Y. Sun, X. Jiang, and J. Li. 2008. Collective Forest Tenure Reform in China: Analysis of Pattern and Performance. Forestry Economics9: 27-38. (In Chinese.) $\mathrm{Xu}$, J., and A. White. 2004. Understanding the Chinese Forest Market and Its Global Implications. International Forestry Review 6(3-4): ii-iv.

Yin, R., and D. H. Newman. 1997. Impacts of Rural Reforms: The Case of the Chinese Forest Sector. Environment and Development Economics 2(3): 291-305.

Yin, R., J. Xu. 2002. A Welfare Measurement of China's Rural Forestry Reform during the 1980s . World Development 30(10): 1755-1767.

Yoder, J. 2004. Playing with Fire: Endogenous Risk in Resource Management. American Journal of Agricultural Economics 86(4): 933-948.

Yu. X. 2013. Undetermined Center, Non-Working Localities, and Inactive Farmers: The Implementation Failures of China's Reforestation Program. Ph.D Thesis, University of Michigan. Ann Arbor: ProQuest/UMI. (Publication No. 3595373) 